\title{
Correlation Between Salivary Calcium Level and Periodontal Disease. A Case Control Study.
}

\author{
Dr. Abhishek Kandwal ${ }^{1}$, Dr Nidhi singh ${ }^{2}$, Dr. Anirban Chatterjee ${ }^{3}$, \\ Dr Hirak Bhattacharya, ${ }^{4}$ Dr Neha Ajmera ${ }^{5}$ \\ ${ }^{1}$ Assistant Professor Dental Surgery Department MDS Periodontics, \\ Himalayan Institute Of Medical Sciences SRHU Dehradun. \\ ${ }^{2}$ Reader NIMS Dental collage Jaipur drnidhi.singh942@gmail.com \\ ${ }^{3}$ Professor \& head Department of periodontology Oxford dental collage \\ ${ }^{4}$ Professor department of periondontology Institute of dental sciences Bareilly \\ ${ }^{5}$ Reader Department of periodontology Vaidik dental collage and research center Daman
}

\begin{abstract}
:
Introduction and objectives: positive correlation have been seen between high salivary calcium content and periodontal disease. This study was designed to compare inorganic salivary calcium, phosphate, flow rate and ph, of paraffin wax stimulated saliva of patients with gingivitis; mild periodontitis; moderate periodontitis; severe periodontitis.

Methods: the present study consisted of 125 patients aged between 28-42 years and were divided into five groups; control, gingivitis, mild periodontitis; moderate periodontitis and severe periodontitis. Plaque index, gingival index, clinical attachment loss and orthopentomogram scores were recorded. Salivary calcium; salivary phosphate; ph and flow rate was also observed.

Results: A statistically significant relation was seen between salivary calcium, phosphate and flow rate in patients with gingivitis, mild periodontitis; moderate periodontitis and severe periodontitis. no statistically significant relation was found for salivary ph levels.

Conclusion: Patients who have increased salivary parameters are more prone to risk of periodontal disease ,than those with reduced salivary parameters.
\end{abstract}

Keywords: Periodontitis; Salivary calcium; Salivary phosphate; Ph; Flow rate, Dentistry.

\section{Introduction}

Saliva was considered one of the most easily assesable yet least studied bodily ${ }^{(1)}$ But as shown by recent surge in diagnostics, saliva is a promising body fluid, which could serve as a potential source for screening various diseases including periodontal diseases i.e. gingivitis and periodontitis.Diagnosing the subjects at risk, gives a leeway in clinical diagnosis to avoid their possible transition to diseased state. A periodontal diagnostic tool provides pertinent information for differential diagnosis, localization of disease, and severity of infection. These diagnostic information in turn serve as basis for treatment planning and provide a means for accessing the effectiveness of the periodontal therapy. Current clinical diagnostic parameters that were introduced more than five decade ago continue to function as the basic model for periodontal diagnosis in clinical practice even today. They include probing pocket depths, bleeding on probing, clinical attachment levels, plaque index, and radiographs that quantify alveolar bone levels. ${ }^{3}$ Albeit easy to use, cost-effective and relatively non-invasive, clinical attachment loss evaluated by the periodontal probe measures damage from past episodes of destruction. It requires a 2- to 3-mm threshold change before a site can be deemed as having experienced significant breakdown. ${ }^{(2)}$ Therefore, there is a requirement of developing new screening or diagnostic tools which are non-invasive, reliable, economic and can be incorporated in clinical practice, andcould be used as a risk predictor of periodontal disease. Saliva may offer the basis for a patient specific diagnostic test for periodontitis. ${ }^{(3)}$

Very less number of clinical trials has been conducted for the association between salivary calcium levels and periodontal health. Clinical study conducted by Sewon L A reported a positive correlation between salivary calcium and periodontal disease. Khalil reported a similar finding in his study. ${ }^{(4,5)}$ On the contrary Kamat et al and Sudhir Shetty reported a negative correlation for the same. ${ }^{(6,7)}$ There is very limited research in this field and hence the aim of the present study was To evaluate, if there is any correlation between salivary calcium level and periodontal disease and whether it can be used as a screening tool for periodontal diseases. 


\section{Material and method}

A total of 125 patients; 60 females and 65 males were screened for this study. Five groups; were formed 25 individuals in each were allotted. Group 1: Healthy / Control group; Group 2: Gingivitis group; Group 3: Mild Periodontitis group ; Group 4: Moderate Periodontitis group ; Group 5: Severe Periodontitis group.

The study protocol was in accordance with the declaration of Helsinki 1964 revised in year 2000 and 2008.

\section{Inclusion criteria:}

1) Subjects aged between 25 - 60 yrs.

2) Subjects who have not used any chemical plaque control aids and periodontal treatment for past 6 months.

3) Subjects who have not taken antibiotic therapy for minimum of 6 months.

4) Subjects with minimum number of 20 teeth.

\section{Exclusion criteria:}

1) Subjects with history of smoking.

2) Subjects with systemic diseases like diabetes, asthma, cardio vascular disorders and bony pathology.

3) Subjects on calcium supplements.

4) Women who have attained menopause.

5) Pregnant women and lactating mother.

The periodontal health of the patients was analyzed by following parameters ${ }^{(9-12)}$

1. Plaque index (P.I)

2. Gingival index (G.I)

3. Clinical attachment loss (CAL)

4. Orthopentomogram findings (OPG)

Salivary parameter analysed were. ${ }^{(4,5)}$

1. Salivary calcium level

2. Salivary phosphate level

3. Salivary $\mathrm{pH}$

4. Salivary flow rate

The statistical analysis was done using SPSS (Statistical Package for Social Sciences) Version 15.0 statistical Analysis Software. Analysis of Variance (ANOVA): The ANOVA test was used to compare the within group a Post-Hoc Tests (Tukey-HSD) was employed to study diffence between the groups.

\section{Results}

Group I comprised of $25(20 \%)$ systemically healthy patients with healthy periodontium. Group II comprised of $25(20 \%)$ patients with gingivitis. Group II, III and IV comprised of $25(20 \%)$ patients each with mild, moderate and severe periodontitis respectively. The study groups were analyzed by means of ANOVA for plaque index, gingival index \& clinical attachment loss. The findings are reported as following; The mean plaque index scores for Group I was 1.00 while for Group II, III, IV and V, the mean values were $1.84 \pm 0.37,1.89 \pm 0.00,2.68 \pm 0.48$ and $3.00 \pm 0.00$ respectively. Analysis of variance (ANOVA) revealed a statistically significant intergroup difference $(\mathrm{F}=293.93 ; \mathrm{p}<0.001)$. Table -1

Group I had mean gingival index (GI) value of $1 \pm 0$; while Group II reported a mean GI of $2.48 \pm$ 1.51. In Groups III, IV and V, the mean GI was $2.5 \pm 0.00,2.60 \pm 0.50$ and $2.72 \pm 0.46$ respectively. Analysis of variance (ANOVA) reporting a statistically significant intergroup difference $(F=85.97 ; p<0.001)$. (Table -1$)$

Group I and II observed no clinical attachment loss (CAL), with a mean score of 0.00 . While Group III; group IV and group V reported a mean CAL score of $1 \pm 0,1.96 \pm 0.20$ and $3.00 \pm 0.0$ respectively. On analyzing the CAL mean scores by ANOVA; it revealed a statistically significant intergroup difference $(\mathrm{F}=5263.50 ; \mathrm{p}<0.001) . \quad($ Table -1.$)$

10 between group comparisons were formed and analyzed for plaque index, gingival index and clinical attachment loss by means of Post Hoc Tukey test.

Between groups comparisons (Tukey HSD) for plaque index (PI) revealed a statistically significant difference for all the comparisons except between Group I vs Group III; Group II vs Group III; Group III vs Group V and; Group IV vs Group V. The between groups comparisons (Tukey HSD) for GI revealed a statistically significant difference for all the comparisons except between Group II vs Group III, and Group IV and Group V. Also a statistically significant difference for clinical attachment loss (CAL) was observed for all the group comparisons expect between Group I and Group II using between groups comparisons (Tukey HSD). 
On applying analysis of variance (ANOVA) for comparing mean salivary calcium level; a mean \pm S.d for Group I of $4.02 \pm 0.32$; Group II of $4.36 \pm 0.29$; Group III of $4.92 \pm 0.41$; Group IV of $5.52 \pm 0.58$; and Group V of $6.26 \pm 0.53$ was observed. A gradual increase in salivary calcium levels was observed from healthy (Group I) to severe periodontitis (Group V) groups, showing a statistically significant intergroup difference $(\mathrm{F}=104.07 ; \mathrm{p}<0.001)$. (Table $-3 \&$ Chart -1$)$

Mean \pm S.d for salivary phosphate in group I was $17.94 \pm 0.64$; group II $18.26 \pm 0.43$; group III $18.27 \pm 0.51$; group IV $18.45 \pm 0.70$ and group V $18.61 \pm 0.70$. salivary phosphate levels were observed to be maximum in Group III and minimum in Group I. A statistically significant variability was observed among groups $(\mathrm{F}=12.849 ; \mathrm{p}<0.001)$.

(Table -3 \& Chart -1)

A gradual increase in salivary $\mathrm{pH}$ was observed from healthy (Group I) to severe periodontitis (Group V) groups, , group I; $7.18 \pm 0.08$; Group II; $7.20 \pm 0.10$; Group III $7.24 \pm 0.11$; group IV $7.29 \pm 0.12$; and group V; $7.52 \pm 0.13$; showing a statistically significant intergroup difference $(F=38.855 ; p<0.001)$. (Table -3 \& Chart -1)

The salivary flow rate was observed to be increasing gradually from Group I to Group IV, group I had a salivary flow of $1.48 \pm 0.13$ units ; group ii had $1.89 \pm 0.36$; group iii had $2.29 \pm 0.33$; group iv had $2.97 \pm$ 0.56 ; however, the mean value of Group V was $2.91 \pm 0.53$; lower as compared to Group IV. There was a Statistically significant variability (ANOVA) observed among the groups. (Table $-3 \&$ Chart -1 )

Between group comparisons (Tukey HSD) revealed statistically significant intergroup differences for salivary calcium levels; except for Group I vs Group II. The concentration of salivary calcium was reported to be in following order. (Table 4.)

\section{Group I < Group II < Group III < Group IV < Group V}

Between group comparisons for phosphate levels showed statistically significant intergroup differences for Group I vs Group III; Group II vs Group III only . The order of mean salivary phosphate levels was :

\section{Group III > Group V $~$ Group IV Group II $\geq$ Group I}

For salivary $\mathrm{p} \overline{\mathrm{H}}$, no statistical significant results were obtained . though there was diffrence in mean but it was not large enough to be of any significance ( $\mathrm{p} 0.54$ ).

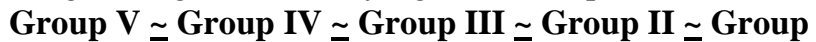

Comparison of mean salivary flow rates revealed statistically significant differences for all the comparisons except that between Group I and Group II; Group II vs Group III; Group IV vs Group V. The order of mean salivary flow rates in different groups was:

\section{Group IV Group V > Group III > Group II > Group I.}

\section{Disscussion}

Salivary calcium have been believed to play a crucial role in homeostasis of oral environment. It has been advocated to affect the caries profile and periodontal status of an individuals. Assessment of Salivary calcium level has been recognized as a potential screening test for candidates with risk of periodontitis. Legendry works of Beck and Wainwright 1934, 1937 in saliva composition ; provided some guidelines to asses and analyze its inorganic constituents like calcium and phosphate. ${ }^{(13,14)}$ Calcium concentration cannot be assed as such, it depends on numerous factors. Factors such as whether secretion was a mixture of all of the salivary gland or from a specific salivary gland; whether saliva was stimulated or unstimulated; How much time lapsed after collection of saliva sample. Whether individuals were slow secretors or fast secretors; How much carbon dioxide loss in sample has occurred ; Diet of the individuals and Systemic conditions. ${ }^{(15-20)}$

There is multitude of views regarding the pathogenesis of periodontal disease; role of salivary calcium had been recognized in past decades as an important factor in progession of periodontitis and over all dental health in industrialized countries. ${ }^{21,22)}$ An increase level of salivary calcium has been reported to be closely associated with rapidly mineralizing plaque and an increased risk of developing periodontitis.

Progression of periodontitis was considered as a transition from stages of gingivitis to alveolar bone loss ; but epidemiological studies have shown that adult population which mostly suffers from gingivitis has relatively less generalized periodontitis transition; on the contrary individuals with healthy periodontium sometime reports with severe isolated alveolar bone defects. This could be probably attributed to the specific periodontogenic microorganism. ${ }^{(23)}$ As it was impossible to induce chronic periodontitis by subcutaneous inoculation of specific periodontogenic pathogens the former explanation does not hold valid. ${ }^{(24)}$

On the other hand placement of sub gingival ligature can induce chronic periodontitis like disease. ${ }^{(25)}$ This occurs as the ligature act as a nidus for plaque accumulation and calculus formation; resulting in extension of gingival inflammation deep into connective tissue initiating periodontitis. In rapid 
plaque formers this sub gingival biofilm rapidly calcify and is difficult to remove by regular home care methods. Sub gingival plaque behaves similarly to a sub gingival ligature in predisposing to periodontal disease. Rapid plaque formation has been proved to promote a higher calcium content of the saliva thus identifying cases with risk of possible periodontitis transition .

Mandel concluded in his study that high saliva concentration was found in heavy calculus former then in slow formers .2 Sewon L A et al reported that calcium concentration of supragingival plaque was higher in adult periodontitis patients when compared with juvenile periodontitis. ${ }^{(26)}$ Also high calcium concentration of plaque is associated with low caries experience. ${ }^{(27)}$

In the present study, when inorganic salivary calcium content was analyzed in patients at different stages of periodontal disease, the results showed a statistically significant increase in calcium as compared to control group. These findings are in accordance with the works of Khalill et al, Sewon La et al and Endre Kiss. ${ }^{(5,28,29)}$

Present study also proposed a linear increase in salivary calcium level with increase in severity of periodontal disease. As the gingival inflammation extended deeper to involve connective tissues and alveolar bone a significant liner increase in salivary calcium was found.

The increase salivary calcium level can be associated with increasing sub gingival calcification potential which results in progression of gingivitis to periodontitis. Endre kiss in his study concluded that salivary calcium and phosphate concentration increase with age showing peak values around menopause. ${ }^{(29)}$ Salivary calcium seems to increase with age may be explained by the hypothesis which states that a decrease in skeletal bone density, seen often in elderly people, may increase the amount of calcium in saliva. However, this phenomenon is not completely clear and needs further studies.

There is data on salivary calcium of different study populations with decreasing bone mineral density, such as patients with rheumatoid arthritis, heavy smokers and women in menopausal ages. ${ }^{(27,29)}$ They all have higher means of salivary calcium level when compared to age-matched counterparts. It is found that hormone replacement therapy, which has a stabilizing effect on calcium content of bone, has a similar effect on salivary calcium. Aforementioned concerned were taken care by excluding all of the risk groups.

On the contrary to the findings of present study Kamat et al and Sudhir shetty et al reported that with increase in gingival inflammation salivary calcium level reported a decrease. ${ }^{(6,7)}$

Similar to the pattern of salivary calcium levels ; salivary phosphate level also reviled a positive linear correlation with increase in severity of periodontal disease. Kamat et al and Sudhir shetty et al reported a increase in phosphate level but is failed to reach any significant; while in present study a significant relation was achieved. ${ }^{(6,7)}$

Salivary flow also reported a increase with severity of periodontal disease. While a study conducted by Endre kiss reported no change in flow rate with age and showed that flow rate did not correlated with calcium concentration; no such criteria were not evaluated in the present study. ${ }^{(29)}$

Salivary ph reported no statistically significant difference; these results were in accordance with study of Sudhir Shetty et al. ${ }^{(7)}$ Salivary Ph has a crucial role in homeostasis of calcium in saliva; ph increase favour calcium deposition as sub gingival band of calculus and decrease in ph favours dissolution of calcium from hydroxyappetite crystals of enamel leading to dental decay. Results of present study give evidence that individuals with increased salivary parameters ; i.e. salivary calcium; salivary phosphate, higher ph ; high flow and poor oral hygiene are at a higher risk of developing periodontal disease. In this individuals calcification of sub gingival bioflim is faster while on the other side it also favour remineralisation of dental decay thus decreasing decay process.

On examining the findings of current study it was concluded that Salivary calcium level reached a statistically significant relation with severity of periodontal disease. Clinical attachment level and OPG score correlated positively with increase in salivary calcium level indicating association of increase salivary calcium with periodontal destruction .

Salivary phosphate level followed similar trend and was reported to be increasing with worsening of cal scores and OPG scores.. Salivary Ph showed no statistically significant difference for various groups under observation. Salivary flow rate showed increase with increae in severity of periodontal disease.

Thus to summarize it can be said that estimation of salivary calcium and phosphate levels may be used as a screening test to identify individuals at risk of periodontitis. Larger longitudinal studies are required to confirm and strengthen the association attained by present study .

\section{References}

[1]. Mandel ID. The diagnostic uses of saliva. J Oral Pathol Med 1990;19(3):119-25.

[2]. Mordohai N, Reshad M, Jivraj S, Chee W. Factors that affect individual tooth prognosis and choices in contemporary treatment planning. Br Dent J. 2007;202:63-72

[3]. Kaufman E, Lamster IB. Analysis of saliva for periodontal diagnosis: A review. J Clin Periodontol 2000;27:453-65. 
[4]. Sewon LA, Karjalkainen SM, Sainio M, Seppa O. Calcium and other salivary factors in periodontitis - affected subjects prior to treatment. J Clin Periodontol 1995; 22:267-70.

[5]. Khalili J, Biloklytska F. Salivary calcium : a risk indicator in periodontal disease. Clin chem. Lab med 2010;48:1361-2.

[6]. Kamat N V. Chemical studies in periodontal disease. Qualitative evaluation of calcium, phosphrous and ALP in normal and inflamed human gingival. J. Indian .Dent .Asso.1979; 51:15-8.

[7]. Shetty S . Quantitative evaluation of salivary calcium, phosphorous, protein and ph in health and diseased periodontitis. Annals and essences of dentistry; 2010;2.4:21-4.

[8]. World medical association declaration of Helsinki ethical principles for medical research involving human subjects . 59th WMA General Assembly, Seoul, October 2008.

[9]. Silness P , Loe H . Periodontal disease in pregnancy. Acta Odontol Scan 1964;22:121.

[10]. Loe H: The gingival index, the plaque index and the retention index system, J Periodontol 1967;38(suppl):610.

[11]. Armitage G.C. Periodontal diagnosis and classification of periodontal disease. Periodontol 2000.2004;34:9-21.

[12]. Sewon L, Parvinen T. The prevalence of periodontal bone loss in finnish adults measured using simplified radiographic criteria . Proceding of Finnish Dental Society. 1988; 84:suppl (II).

[13]. Beck H, Wainwright W.W. A critical discussion of former salivary calcium studies and their values in establishment of normal standards. J Dent Res. 1934;14:387.

[14]. Beck H , Wainwright W.W. Critical decision of former salivary phosphorus studies and their values in establishment of normal standards. J Dent Res.1937;17:197-207.

[15]. Beck H. Human saliva. VII . A study of the rate of flow of resting saliva. J. Dent. Res. 1939;18:431.

[16]. Beck H. Total calcium content of resting saliva of 650 healthy individuals. J Dent Res. 1943;22:397.

[17]. Wainwright WW. A study of rate of flow of activated saliva . J Dent Res 1939;18:441.

[18]. Wainwright WW . Inorganic phosphorus content of resting saliva of 650 healthy individuals. J Dent Res.1943;22:403.

[19]. Becks H, Wainwright WW. Rate of flow of resting saliva of 650 health Individuals. J. Dent. Res. 1943;22:391.

[20]. Ericson S. The variability of the human parotid flow rate on stimulation with citric acid, with special reference to taste. Arch Oral Biol. 1971;16:9.

[21]. Afonsky D. Saliva and its relation to oral health . University of Alabama Press, Birmingham.1961:785.

[22]. Shannon IL. Saliva : Composition and secretions .Monographs in oral sciences, 1974:2.

[23]. Loesche WJ: Chemotherapy of dental plaque infections. Oral Sci Rev 1976, 9:63-107.

[24]. Mayard D, Bridge BC. Ecological relationships of bacteria involved in a simple, mixed anaerobic infection, Infect Immun 1980;27:44-50.

[25]. Kornman KS, Holt SC, Robertson PB. The Microbiology of Ligature-induced Periodontitis in the Cynomolgus Monkey, J Periodont Res 1981;16:363-71.

[26]. Aguirre A, Testa Weintraub LA . Sialochemistry: A diagnostic tool? Crit Rev Oral Biol Med 1993;4(3/4):343-50.

[27]. Sewon LA Soderling, Karjalainen AM. A mineral related feature of young plaque characteristic to periodontitis affected adults. J Periodontal 1990;61:42-4.

[28]. Irwin D Mandel . Calculus update: prevalence, pathogenicity and prevention . J American Dent Assoc. 1995;126:573-9.

[29]. Sewon LA, Soderling, Karjalainen AM. Comparative study on mineralization related intra oral parameters in periodontitis affected and periodontitis free adults. Scand. J. Den Res 1990;98:305-12

[30]. Endre Kiss. Salivary Electrolytes, Focused on Salivary Calcium Level and the Periodontal State in Healthy Smoking and NonSmoking Women Available at: http://www.phd.szote.u-szeged.hu/Klinikai_DI/Disszertaciok/2010/de_Kiss_Endre.pdf

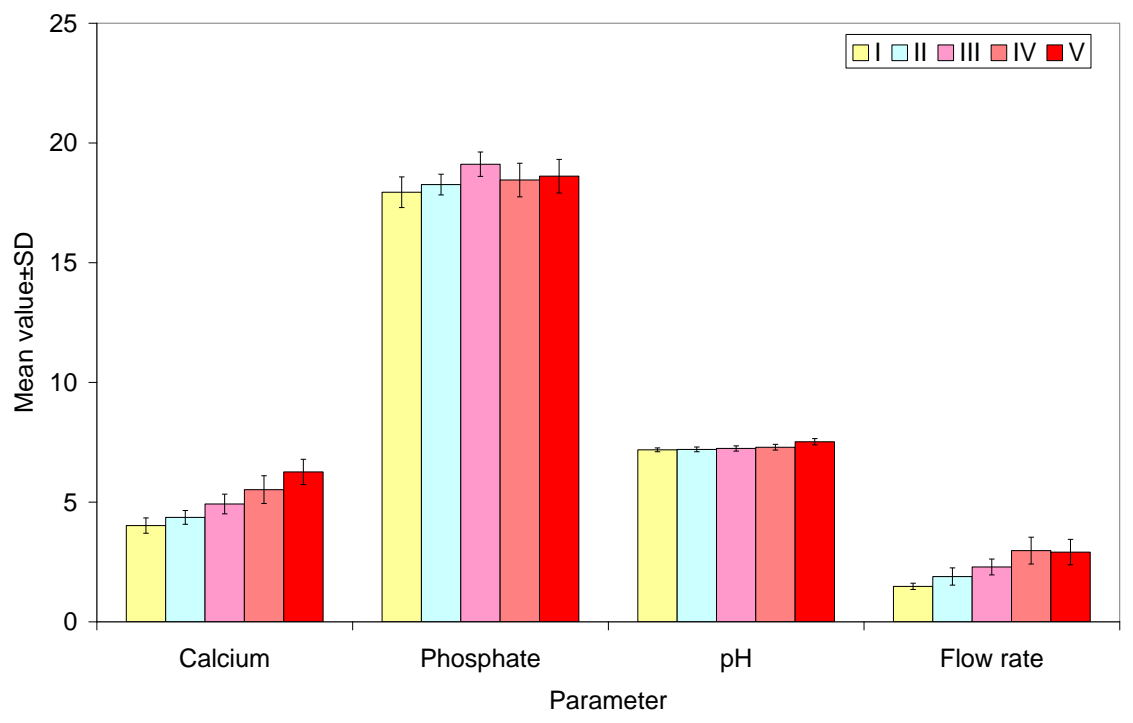

Chart 1. salivary parameters in various groups

Table 1: Mean Plaque Index, Gingival Index and Clinical Attachment Loss

\begin{tabular}{|l|l|l|l|l|l|l|l|}
\hline \multirow{2}{*}{ S.No. } & \multirow{2}{*}{ Group } & \multicolumn{2}{l}{ PI } & GI & CAL \\
\cline { 3 - 8 } & & Mean & SD & Mean & SD & Mean & SD \\
\hline 1. & I & 1.00 & 0.00 & 1.00 & 0.00 & 0.00 & 0.00 \\
\hline 2. & II & 1.84 & 0.37 & 2.48 & 0.51 & 0.00 & 0.00 \\
\hline 3. & III & 1.89 & 0.00 & 2.00 & 2.50 & 1.00 & 0.00 \\
\hline 4. & IV & 2.68 & 0.48 & 2.60 & 0.50 & 1.96 & 0.20 \\
\hline
\end{tabular}




\begin{tabular}{|c|c|c|c|c|c|c|c|}
\hline 5. & $\mathrm{~V}$ & & 0.00 & 2.72 & 0.46 & 3.00 & 0.00 \\
\hline \multirow{2}{*}{$\begin{array}{l}\text { Group } \\
\text { (I) }\end{array}$} & \multirow{2}{*}{$\begin{array}{l}\text { Group } \\
\text { (J) }\end{array}$} & \multicolumn{2}{|l|}{ PI } & \multicolumn{2}{|l|}{ GI } & \multicolumn{2}{|l|}{ CAL } \\
\hline & & $\begin{array}{l}\text { MD } \\
\text { (I-J) }\end{array}$ & p & $\begin{array}{l}\text { MD } \\
\text { (I-J) }\end{array}$ & p & $\begin{array}{l}\text { MD } \\
\text { (I-J) }\end{array}$ & p \\
\hline \multirow[t]{4}{*}{ I vs } & II & -0.840 & $<0.001$ & -1.480 & $<0.001$ & 0.000 & 1.000 \\
\hline & III & 0.000 & 1.000 & -1.000 & $<0.001$ & -1.000 & $<0.001$ \\
\hline & IV & -1.680 & $<0.001$ & -1.600 & $<0.001$ & -1.960 & $<0.001$ \\
\hline & $\mathrm{V}$ & -2.000 & $<0.001$ & -1.720 & $<0.001$ & -3.000 & $<0.001$ \\
\hline \multirow[t]{3}{*}{ II vs } & III & 0.840 & 0.28 & 0.480 & $<0.001$ & -1.000 & $<0.001$ \\
\hline & IV & -0.840 & $<0.001$ & -0.120 & 0.797 & -1.960 & $<0.001$ \\
\hline & V & -1.160 & $<0.001$ & -0.240 & 0.174 & -3.000 & $<0.001$ \\
\hline \multirow[t]{2}{*}{ III vs } & IV & -1.680 & $<0.001$ & -0.600 & $<0.001$ & -0.960 & $<0.001$ \\
\hline & $\mathrm{V}$ & -2.000 & 0.12 & -0.720 & $<0.001$ & -2.000 & $<0.001$ \\
\hline IV vs & V & -0.320 & 0.001 & -0.120 & 0.797 & -1.040 & $<0.001$ \\
\hline
\end{tabular}

\begin{tabular}{|l|l|l|l|}
\hline F (ANOVA) & 293.35 & 85.97 & 5263.50 \\
\hline "p" & $<0.001$ & $<0.001$ & $<0.001$ \\
\hline
\end{tabular}

Table 2 : Between Group comparison of PI, GI and CAL (Tukey HSD)

Table 3: Mean salivary calcium and phosphate levels, mean salivary $\mathrm{pH}$ and mean salivary flow rates in different study group.

\begin{tabular}{|c|c|c|c|c|c|c|c|c|c|}
\hline \multirow[t]{2}{*}{ S.No. } & \multirow[t]{2}{*}{$\begin{array}{l}\text { Gro } \\
\text { up }\end{array}$} & \multicolumn{2}{|c|}{$\begin{array}{l}\text { Salivary Calcium } \\
\text { (units) }\end{array}$} & \multicolumn{2}{|c|}{$\begin{array}{l}\text { Salivary Phosphate } \\
\text { (units) }\end{array}$} & \multicolumn{2}{|c|}{ Salivary pH } & \multicolumn{2}{|c|}{$\begin{array}{l}\text { Salivary flow rate } \\
\text { (units) }\end{array}$} \\
\hline & & Mean & SD & Mean & SD & Mean & SD & Mean & SD \\
\hline 1. & I & 4.02 & 0.32 & 17.94 & 0.64 & 7.18 & 0.08 & 1.48 & 0.13 \\
\hline 2. & II & 4.36 & 0.29 & 18.26 & 0.43 & 7.20 & 0.10 & 1.89 & 0.36 \\
\hline 3. & III & 4.92 & 0.41 & 18.27 & 0.51 & 7.24 & 0.11 & 2.29 & 0.33 \\
\hline 4. & IV & 5.52 & 0.58 & 18.45 & 0.70 & 7.29 & 0.12 & 2.97 & 0.56 \\
\hline 5. & $\mathrm{~V}$ & 6.26 & 0.53 & 18.61 & 0.70 & 7.52 & 0.13 & 2.91 & 0.53 \\
\hline \multicolumn{2}{|c|}{$\mathrm{F}$ (ANOVA) } & \multicolumn{2}{|l|}{104.07} & \multicolumn{2}{|l|}{12.849} & \multicolumn{2}{|l|}{98.855} & \multicolumn{2}{|l|}{60.739} \\
\hline \multicolumn{2}{|c|}{ "p" } & \multicolumn{2}{|l|}{$<0.001$} & \multicolumn{2}{|l|}{$<0.001$} & \multicolumn{2}{|l|}{0.02} & \multicolumn{2}{|l|}{$<0.001$} \\
\hline
\end{tabular}

Table 4: Between Group comparison of physicochemical characteristics of saliva (Tukey HSD)

\begin{tabular}{|c|c|c|c|c|c|c|c|c|c|}
\hline \multirow{2}{*}{$\begin{array}{l}\text { Group } \\
\text { (I) }\end{array}$} & \multirow[t]{2}{*}{ Group $(J)$} & \multicolumn{2}{|l|}{$\mathbf{C a}$} & \multicolumn{2}{|l|}{$\mathrm{PO}_{4}$} & \multicolumn{2}{|l|}{ pH } & \multicolumn{2}{|c|}{ Flow rate } \\
\hline & & $\begin{array}{l}\text { MD } \\
\text { (I-J) }\end{array}$ & p & $\begin{array}{l}\text { MD } \\
\text { (I-J) }\end{array}$ & $\mathbf{P}$ & $\begin{array}{l}\text { MD } \\
\text { (I-J) }\end{array}$ & $\mathbf{p}$ & $\begin{array}{l}\text { MD } \\
\text { (I-J) }\end{array}$ & $\mathbf{p}$ \\
\hline \multirow[t]{4}{*}{ I vs } & II & -0.35 & 0.048 & -0.31 & 0.359 & -0.02 & 0.937 & -0.41 & 0.005 \\
\hline & III & -0.90 & $<0.001$ & -1.17 & $<0.001$ & -0.06 & 0.241 & -0.81 & $<0.001$ \\
\hline & IV & -1.50 & $<0.001$ & -0.51 & 0.030 & -0.11 & 0.006 & -1.49 & $<0.001$ \\
\hline & $\mathrm{V}$ & -2.25 & $<0.001$ & -0.67 & 0.002 & -0.34 & 0.009 & -1.43 & $<0.001$ \\
\hline \multirow[t]{3}{*}{ II vs } & III & -0.56 & $<0.001$ & -0.85 & $<0.001$ & -0.04 & 0.697 & -0.40 & 0.007 \\
\hline & IV & -1.15 & $<0.001$ & -0.19 & 0.794 & -0.08 & 0.058 & -1.08 & $<0.001$ \\
\hline & $\mathrm{V}$ & -1.90 & $<0.001$ & -0.35 & 0.245 & -0.32 & 0.03 & -1.02 & $<0.001$ \\
\hline \multirow[t]{2}{*}{ III vs } & IV & -0.60 & $<0.001$ & 0.66 & 0.002 & -0.04 & 0.615 & -0.68 & $<0.001$ \\
\hline & $\mathrm{V}$ & -1.34 & $<0.001$ & 0.50 & 0.033 & -0.28 & 0.02 & -0.62 & $<0.001$ \\
\hline IV vs & $\mathrm{V}$ & -0.75 & $<0.001$ & -0.16 & 0.882 & -0.23 & 0.04 & 0.06 & 0.986 \\
\hline
\end{tabular}

